\title{
KOMPARASI UNJUK KERJA PERALATAN SPEKTROFOTOMETER UV-VIS PERKIN ELMER LAMBDA 3 DENGAN HITACHI U-2900 PADA PENENTUAN TOTAL PHENOLIC CONTENT
}

\author{
Lia Agustin ${ }^{1}$, Rilla Agustina ${ }^{2}$ \\ 1,2 Jurusan Teknik Kimia, Politeknik Negeri Malang \\ ${ }^{1}$-rilla_raihan@yahoo.com, ${ }^{2}$ link_deus@yahoo.com \\ (Artikel diterima: Oktober 2019, direvisi: September 2019, diterima untuk terbit: Januari 2020)
}

\begin{abstract}
Abstrak - Komparasi dua alat Spektrofotometer dengan merk dan tahun pemakaian yang berbeda diperlukan untuk mengetahui unjuk kerja alat. Pengujian dilakukan pada penentuan kandungan fenolik total (TPC) metode Folin-Ciocalteu. Hasil analisa TPC dari dua alat spektrofotometer kemudian dikomparasi dengan menggunakan uji paired t-test. Uji paired ttest merupakan uji membandingkan rata-rata hasil pengujian dari kedua alat tersebut. Hasil pengujian dikatakan akurat apabila hasil keduanya tidak berbeda signifikan. Uji t berpengaruh positif dan signifikan apabila hasil perhitungan t hitung lebih besar dari $\mathrm{t}$ tabel ( $\mathrm{t}$ - hitung $>\mathrm{t}$ - tabel). Hasil penelitian menunjukkan nilai d rata-rata sebesar 85.934, dan standar deviasi bernilai 51130.27368. Nilai tersebut digunakan untuk menghitung nilai t. Nilai t yang didapatkan sebesar 0,0053 . Dengan nilai $\alpha$ sebesar 0,05 maka didapat $\mathrm{t}$ tabel sebesar 2,262. Karena nilai T-hitung < T-tabel, maka H0 diterima dan H1 ditolak, sehingga dapat dikatakan kinerja hasil uji kedua alat sama.
\end{abstract}

Kata kunci: Komparasi, TPC, Folin-Ciocalteu, Spectrofotometer UV/Vis, uji paired t-test

\section{Pendahuluan}

Laboratorium instrumentasi Jurusan Teknik Kimia Politeknik Negeri Malang memiliki peralatan spektofotometer uv-vis pemakaian tahun 1989 dengan merk Perkin Elmer lambda 3 dan tahun 2011 dengan merk Hitachi U-2900. Pada penelitian ini pengujian kinerja kedua alat tersebut dilakukan pada analisa kandungan fenolik total. Sehingga hasil analisa kandungan fenolik total pada kedua alat spektrofotometer uv/vis tersebut dikomparasi menggunakan uji paired t-test. Uji paired t-test merupakan uji membandingkan rata-rata hasil pengujian dari kedua alat tersebut. Metode yang dipilih untuk penentuan kandungan fenolik total adalah metode Folin-Ciocalteu. Metode ini merupakan metode yang umum digunakan sebagai standar penentuan kandungan fenolik total karena merupakan metode yang cepat dan sederhana yang dinyatakan sebagai massa ekivalen asam galat tiap mg sampel (Fu,Xu, Gan, Zhang, Xia, dan $\mathrm{Li}, 2011)$. Prinsip dari metode ini adalah reaksi oksidasi senyawa fenol dalam suasana basa oleh pereaksi FolinCiocalteu menghasilkan kompleks berwarna biru yang memberikan serapan kuat pada panjang gelombang $760 \mathrm{~nm}$. Peningkatan intensitas warna biru akan sebanding dengan jumlah senyawa fenolik yang ada dalam sampel (Blainski, Cristiny, dan de Mello, 2013).

\section{Tinjauan Pustaka}

Spektrofotometri sinar tampak (UV-Vis) adalah pengukuran energi cahaya oleh suatu sistem kimia pada panjang gelombang tertentu (Day, 2002). Electron pada ikatan dalam molekul menjadi tereksitasi sehingga berada pada keadaan energy yang lebih tinggi dalam proses menyerap sejumlah energy yang melewati larutan tersebut (Watson, 2010). Spektrum UV-Vis sangat berguna untuk pengukuran secara kuantitatif. Konsentrasi dari analit di dalam larutan bisa ditentukan dengan mengukur absorban pada panjang gelombang tertentu dengan menggunakan hukum Lambert-Beer (Rohman, 2007). Hukum Lambert-
Beer menyatakan hubungan linieritas antara absorban (besarnya sinar radiasi yang terserap oleh zat) dengan konsentrasi larutan analit dan berbanding terbalik dengan transmitan (besarnya sinar radiasi yang melewati zat dan ditangkap detektor).

\section{A. Uji sampel t berpasangan}

Uji-t berpasangan (paired t-test) adalah salah satu metode pengujian hipotesis yang digunakan untuk membandingkan rata-rata (mean) dari dua kumpulan data yang ada dimana kedua kumpulan data tersebut berasal dari 1 kelompok obyek/responden yang sama. Dalam penelitian ini data yang digunakan adalah data fenolik total menggunakan metode Folin-Ciocalteu yang absorbansinya diukur pada panjang gelombang $765 \mathrm{~nm}$ menggunakan kedua spektrofotometer UV/Vis. Rumus untuk menghitung $\mathrm{t}$ :

$$
t=\frac{\bar{d} \sqrt{\mathrm{n}}}{s_{d}}
$$

Di mana :

$$
\begin{aligned}
\bar{d} & =\text { nilai rata-rata dari } \mathrm{d} \\
\mathrm{S}_{\mathrm{d}} & =\text { standar deviasi dari } \mathrm{d} \\
\mathrm{n} & =\text { jumlah data }
\end{aligned}
$$

Pengujian melalui uji t adalah dengan membandingkan $\mathrm{t}$ hitung dengan $t$ tabel pada taraf nyata (taraf Signifikansi) $\alpha=$ 0,05. Menurut Widiyanto (2013), paired sample t-test merupakan salah satu metode pengujian yang digunakan untuk mengkaji keefektifan perlakuan, ditandai adanya perbedaan rata-rata sebelum dan rata-rata sesudah diberikan perlakuan. Langkah pengujiannya adalah sebagai berikut :

1. Menentukan formulasi $\mathrm{H} 0$ dan $\mathrm{H} 1$

- H0 : Hasil uji kedua alat sama

- $\quad$ H1 : Hasil uji kedua alat berbeda secara nyata

2. Tes statistic.

- $\quad$ Jika T-hitung $>$ T-tabel, maka H0 ditolak dan H1 diterima

- $\quad$ Jika T-hitung < T-tabel, maka H0 diterima dan H1 
ditolak

\section{B. Penentuan Total Phenolik Content}

Analisis kandungan fenolik total menggunakan metode Folin-Ciocalteu yang absorbansinya diukur pada panjang gelombang $765 \mathrm{~nm}$ (Pourmorad dkk; 2006). Standar asam galat dibuat dengan variasi konsetrasi dan diukur absorbansinya pada panjang gelombang $765 \mathrm{~nm}$. Asam galat adalah senyawa golongan asam fenolik C6-C1 (en:phenolic acid \} atau hidroksibenzoat, yaitu asam 3,4,5trihidroksibenzoat.

Analisis kandungan fenolik total menggunakan metode Folin-Ciocalteu yang absorbansinya diukur pada panjang gelombang $765 \mathrm{~nm}$. Standar asam galat dibuat dengan variasi konsentrasi 5-125 ppm dan diukur absorbansinya pada panjang gelombang $765 \mathrm{~nm}$. Prosedur pengukuran sampel dilakukan dengan cara menimbang beberapa sampel lalu ditambahkan dengan 0,5 ml metanol, 2,5 $\mathrm{ml}$ aquadest dan 2,5 $\mathrm{ml}$ reagent Folin-Ciocalteau 50\%. Campuran didiamkan selama 5 menit kemudian ditambahkan dengan $2 \mathrm{ml} \mathrm{Na} 2 \mathrm{CO} 3$ $7,5 \%$ dan divorteks lalu diinkubasi selama 15 menit pada suhu $45^{\circ} \mathrm{C}$. Absorbansi sampel diukur pada panjang gelombang $765 \mathrm{~nm}$ dengan menggunakan spektrofotometer UV-VIS. Perhitungan kandungan fenolik total menggunakan rumus berikut Perhitungan kandungan fenolik total menggunakan rumus berikut :

$$
T P C=C . V . f p \cdot g
$$

Di mana : $\mathrm{c}=$ konsetrasi Fenolik (nilai $\mathrm{x}$ )

$$
\begin{aligned}
& \mathrm{v}=\text { volume ekstrak yang digunakan }(\mathrm{ml}) \\
& \mathrm{fp}=\text { Faktor pengenceran } \\
& \mathrm{g}=\text { Berat sampel yang digunakan }
\end{aligned}
$$

Asam galat digunakan sebagai larutan standar karena asam galat merupakan salah satu jenis golongan senyawa phenolik. Yang mana asam galat ini memiliki nama lain pyrogalol. Senyawa ini dapat ditemukan pada daun ek dan anggur dan memiliki aktivitas sebagai antioksidan (penangkal radikal bebas).

Prinsip metode Folin-Ciocalteu adalah reaksi oksidasi dan reduksi kolorimetrik untuk mengukur semua senyawa fenolik dalam sampel uji. ). Fenolat hanya terdapat pada larutan basa, tetapi pereaksi Folin-Ciocalteu dan produknya tidak stabil pada kondisi basa. Selama reaksi belangsung, gugus fenolik-hidroksil bereaksi dengan pereaksi FolinCiocalteu, membentuk kompleks fosfotungstatfosfomolibdat berwarna biru dengan struktur yang belum diketahui dan dapat dideteksi dengan spektrofotometer.

\section{METODE PENELITIAN}

\section{A. Alat}

Alat yang digunakan dalam penelitian yaitu : Spectrofotometer UV-VIS Perkin Elmer Lambda 3 pemakaian tahun 1989, Spectrofotometer UV/VIS Hitachi U2900 pemakaian tahun 2011, Labu ukur, Mikropipet, Gelas Kimia, Botol Vial, Neraca Analitik, Spatula, Incubator Oven.

\section{B. Bahan}

Bahan-bahan yang digunakan yaitu : Aquadest, Methanol, Folin-Ciocalteu's phenol Reagent, Na-Carbonat, Gallic Acid

\section{Pembuatan Larutan Standar Asam Gallat}

Ditimbang Asam Gallat 1 gram, Ditambahkan Aquadest hingga $1000 \mathrm{ml}$ pada labu ukur, Didapatkan larutan induk dengan konsentrasi 1000 ppm.

\section{Preparasi Sampel}

Sampel daun kering dihaluskan/ditumbuk, Kemudian dimaserasi dengan methanol selama 1 hari, kemudian diambil ekstraknya.

\section{E. Penentuan Panjang Gelombang yang mempunyai Serapan Maximum}

- Dipilih salah satu konsentrasi asam galat, kemudian dilakukan preparasi dengan ditambahkan Methanol 0,5 $\mathrm{ml}$, Aquabidest 2,5 ml, Reagent-Folin-Ciocalteu 2,5 ml, didiamkan selama 5 menit

- Ditambahkan Na-carbonat 7,5\% sebanyak $2 \mathrm{ml}$

- Divortex

- $\quad$ Diinkubasi pada suhu $45^{\circ} \mathrm{C}$ selama 15 menit

- Kemudian diukur serapannya dengan spektrofotometer uv/vis pada panjang gelombang 600-850 nm dengan menggunakan blangko.

\section{F. Analisa Hasil}

Penentuan TPC (Total Phenolic Content) dilakukan dengan menggunakan kedua alat Spectrofotometer UV-VIS. Pertama membuat larutan baku (standard) dengan berbagai macam konsentrasi. Kedua melakukan analisis larutan baku. Ketiga mengolah data yang dihasilkan dengan paired $t$ test.

\section{HASIL DAN PEMBAHASAN}

\section{A. Penentuan Panjang Gelombang yang mempunyai Serapan Maximum pada alat Spektrofotometer uv/vis Hitachi U-2900}

Dipilih salah satu dari larutan standar Asam Galat untuk menentukan panjang gelombang yang mempunyai Absorbansi maksimum dimulai dari $650 \mathrm{~nm}$ sampai dengan $850 \mathrm{~nm}$. Dari Grafik hubungan antara Panjang Gelombang dengan Absorbansi didapatkan panjang gelombang yang mempunyai Absorbansi Maximum pada 765,0 nm dengan absorbansi paling tinggi 0,337 .

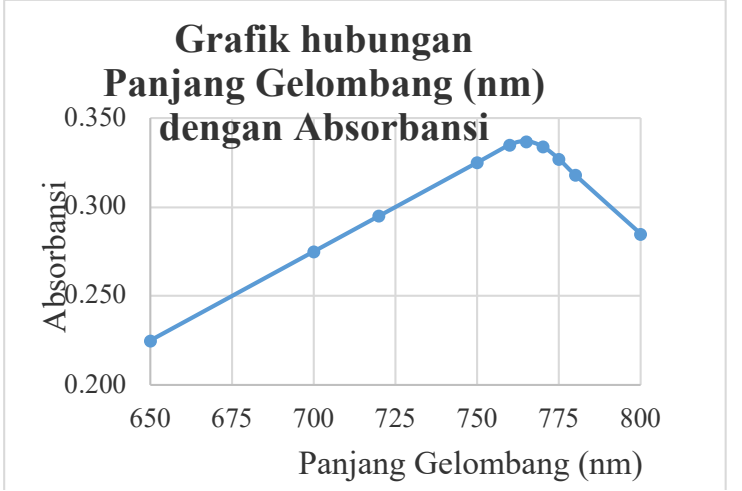

Gambar 1. Grafik Hubungan Panjang Gelombang (nm) dengan Absorbansi pada alat Spektrofotometer uv/vis Hitachi U-2900

\section{B. Penentuan Panjang Gelombang yang mempunyai Serapan Maximum pada alat Spectrofotometer UV-VIS Perkin Elmer Lambda 3}

Dipilih salah satu dari larutan standar Asam Galat untuk 
menentukan panjang gelombang yang mempunyai Absorbansi maksimum dimulai dari $650 \mathrm{~nm}$ sampai dengan $850 \mathrm{~nm}$. Dari Grafik hubungan antara Panjang Gelombang dengan Absorbansi didapatkan panjang gelombang yang mempunyai Absorbansi Maximum pada 765,0 nm dengan absorbansi paling tinggi 0,331 .

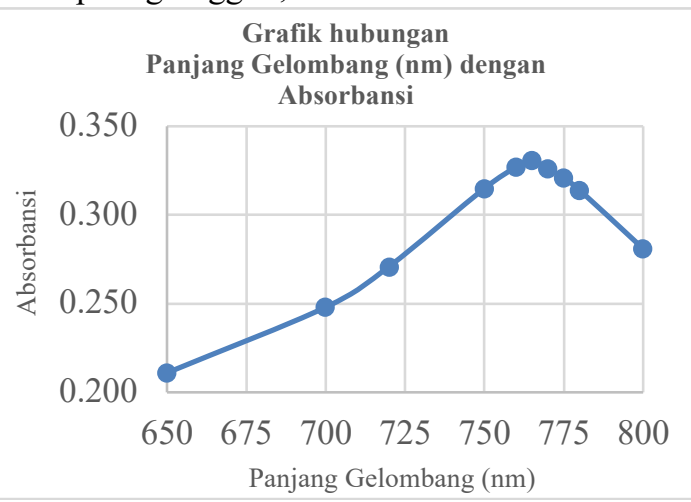

Gambar 2. Grafik Hubungan Panjang Gelombang (nm) dengan Absorbansipada alat Spectrofotometer UV-VIS Perkin Elmer Lambda 3

\section{Hasil percobaan dengan alat Spektrofotometer uv/vis Hitachi U-2900}

Tabel 1 Pengukuran absorbansi standar asam gallat pada panjang gelombang $765 \mathrm{~nm}$

\begin{tabular}{|c|c|c|c|c|}
\hline NO & $\begin{array}{c}\text { Konsentrasi } \\
(\mathrm{ppm})\end{array}$ & ABS I & ABS II & $\begin{array}{c}\text { ABS } \\
\text { RATA2 }\end{array}$ \\
\hline 1 & - & - & - & - \\
\hline 2 & 2 & 0.042 & 0.044 & 0.043 \\
\hline 3 & 4 & 0.094 & 0.092 & 0.093 \\
\hline 4 & 6 & 0.137 & 0.135 & 0.136 \\
\hline 5 & 8 & 0.186 & 0.190 & 0.188 \\
\hline 6 & 10 & 0.230 & 0.232 & 0.231 \\
\hline 7 & 20 & 0.427 & 0.430 & 0.429 \\
\hline 8 & 40 & 0.854 & 0.851 & 0.853 \\
\hline
\end{tabular}

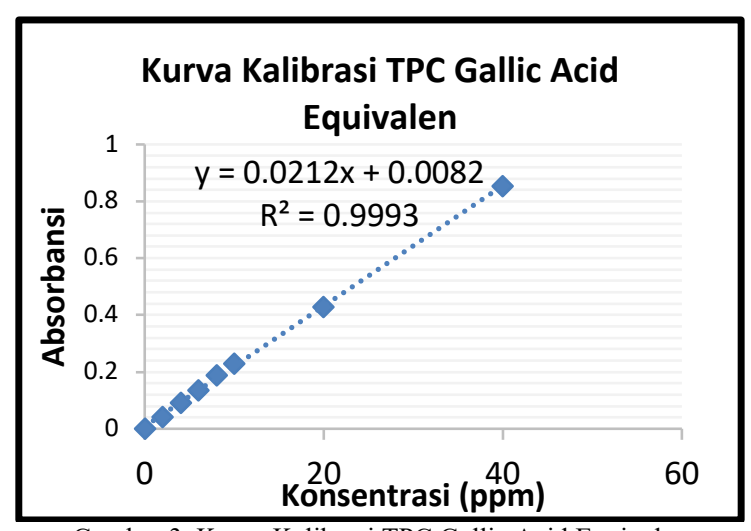

Gambar 3. Kurva Kalibrasi TPC Gallic Acid Equivalen

Dilakukan pengukuran absorbansi larutan standar asam galat dari beberapa konsentrasi yang diukur pada panjang gelombang maksimal yang diperoleh. Hasil pengukuran absorbansi larutan standar asam galat dibuat kurva kalibrasi. Persamaan regresi linear yang diperoleh yaitu $y=0,0212 x+0,0082$ dengan koefisien korelasi (r) 0,9993.

Tabel 2 Perhitungan TPC dengan absorbansi yang diukur dengan Spektrofotometer uv/vis Hitachi U-2900

\begin{tabular}{|l|c|c|}
\hline NO & NAMA & \multirow{2}{*}{ TPC $(\mu \mathrm{g} / \mathrm{g})$} \\
\hline
\end{tabular}

\begin{tabular}{|c|c|c|}
\hline 1 & A1 & 518,026 \\
\hline 2 & B1 & $1,066,085$ \\
\hline 3 & C1 & 549,994 \\
\hline 4 & D1 & 721,751 \\
\hline 5 & E1 & 751,033 \\
\hline 6 & F1 & 588,979 \\
\hline 7 & G1 & 706,245 \\
\hline 8 & H1 & 687,640 \\
\hline 9 & I1 & 697,634 \\
\hline 10 & J1 & 554,395 \\
\hline
\end{tabular}

Tabel 3 Pengukuran absorbansi standar asam galat pada panjang gelombang $765 \mathrm{~nm}$

\begin{tabular}{|c|c|c|c|c|}
\hline NO & $\begin{array}{c}\text { Konsentrasi } \\
(\mathrm{ppm})\end{array}$ & ABS I & ABS II & $\begin{array}{c}\text { ABS } \\
\text { RATA2 }\end{array}$ \\
\hline 1 & - & - & - & - \\
\hline 2 & 2 & 0.034 & 0.039 & 0.037 \\
\hline 3 & 4 & 0.087 & 0.086 & 0.087 \\
\hline 4 & 6 & 0.098 & 0.095 & 0.097 \\
\hline 5 & 8 & 0.157 & 0.154 & 0.156 \\
\hline 6 & 10 & 0.211 & 0.210 & 0.211 \\
\hline 7 & 20 & 0.410 & 0.419 & 0.415 \\
\hline 8 & 40 & 0.801 & 0.798 & 0.800 \\
\hline
\end{tabular}

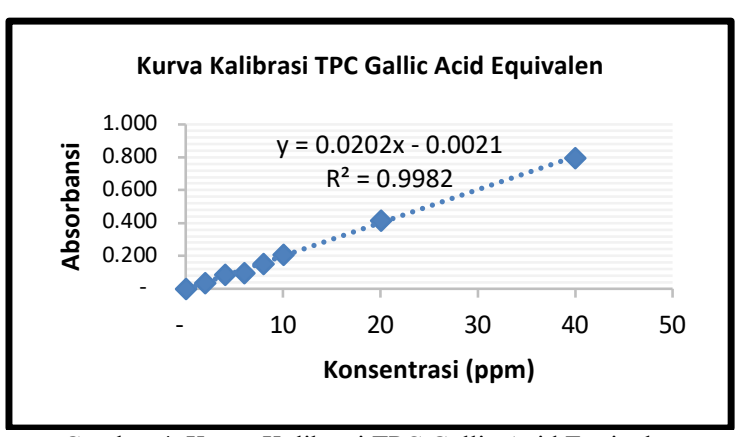

Gambar 4. Kurva Kalibrasi TPC Gallic Acid Equivalen

Dilakukan pengukuran absorbansi larutan standar asam galat dari beberapa konsentrasi yang diukur pada panjang gelombang maksimal yang diperoleh. Hasil pengukuran absorbansi larutan standar asam galat dibuat kurva kalibrasi. Persamaan regresi linear yang diperoleh yaitu $y=0,0202 x-$ 0,0021 dengan koefisien korelasi (r) 0,9982.

Tabel 4 Perhitungan TPC dengan absorbansi yang diukur dengan Spectrofotometer UV-VIS Perkin Elmer Lambda 3

\begin{tabular}{|c|c|c|}
\hline NO & $\begin{array}{c}\text { NAMA } \\
\text { SAMPEL }\end{array}$ & $\begin{array}{c}\text { TPC } \\
(\boldsymbol{\mu g} / \mathbf{g})\end{array}$ \\
\hline 1 & A1 & 510,149 \\
\hline 2 & B1 & 946,221 \\
\hline 3 & C1 & 489,130 \\
\hline 4 & D1 & 650,825 \\
\hline 5 & E1 & 575,088 \\
\hline 6 & F1 & 494,259 \\
\hline 7 & G1 & 641,182 \\
\hline 8 & H1 & 554,565 \\
\hline 9 & I1 & 675,483 \\
\hline 10 & J1 & 445,537 \\
\hline
\end{tabular}

D. Perhitungan Standar Deviasi

Tabel 5 Perhitungan d rata-rata dan standar Deviasi 


\begin{tabular}{|c|c|c|}
\hline $\begin{array}{c}\text { TPC }(\mu \mathrm{g} / \mathrm{g}) \\
\text { Hitachi U-2900 }\end{array}$ & $\begin{array}{c}\text { TPC }(\mu \mathrm{g} / \mathrm{g}) \\
\text { PERKIN ELMER } \\
\text { LAMBDA } 3 \\
\end{array}$ & $\begin{array}{l}\text { Differences } \\
\text { (d) }\end{array}$ \\
\hline 518,026 & 510,149 & 7,877 \\
\hline $1,066,085$ & 946,221 & 119,865 \\
\hline 549,994 & 489,130 & 60,864 \\
\hline 721,751 & 650,825 & 70,925 \\
\hline 751,033 & 575,088 & 175,945 \\
\hline 588,979 & 494,259 & 94,719 \\
\hline 706,245 & 641,182 & 65,063 \\
\hline 687,640 & 554,565 & 133,075 \\
\hline 697,634 & 675,483 & 22,151 \\
\hline 554,395 & 445,537 & 108,858 \\
\hline \multicolumn{2}{|c|}{ rata-rata d } & 85,934 \\
\hline \multicolumn{2}{|c|}{ Standar deviasi, $\mathrm{Sd}$} & 51130.27368 \\
\hline
\end{tabular}

\section{E. Perhitungan nilai t hitung}

$$
\begin{gathered}
t=\frac{\bar{d} \sqrt{\mathrm{n}}}{s_{d}} \\
t=\frac{85.934 \sqrt{10}}{51130.27368} \\
t=0,0053
\end{gathered}
$$

\section{F. Nilai t tabel}

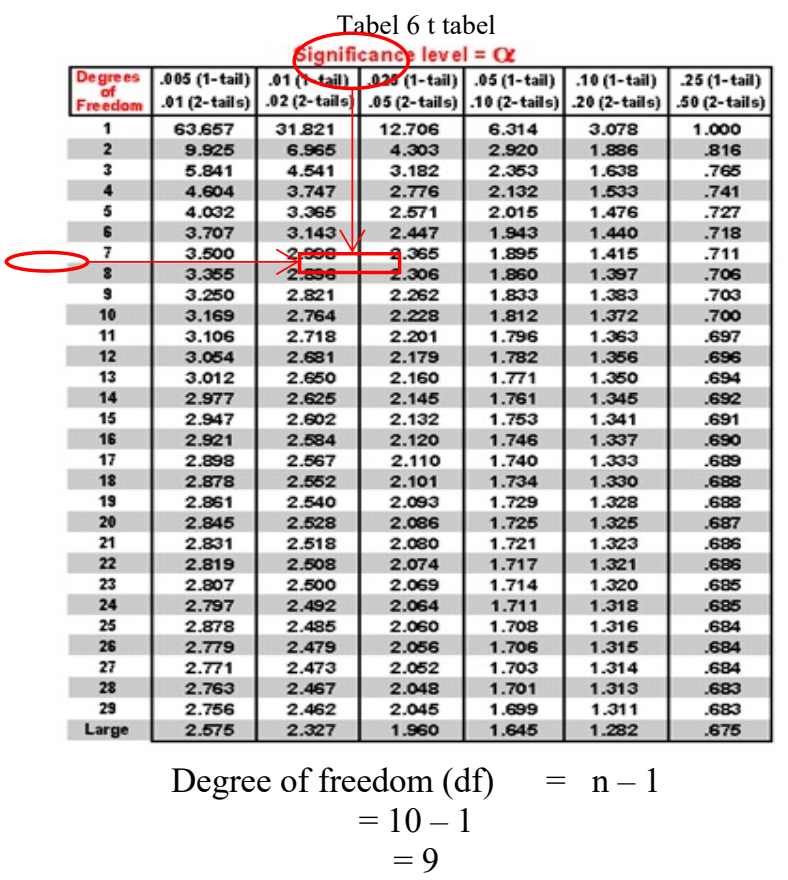

Dengan nilai $\alpha$ sebesar 0,05 maka didapat $t$ tabel sebesar 2,262

\section{G. Hipotesis uji Paired t-test}

Nilai t-hitung $<$ t-tabel, maka H0 diterima dan H1 ditolak sehingga dapat dikatakan kinerja hasil uji kedua alat sama.

\section{KESIMPULAN DAN SARAN}

\section{A. Kesimpulan}

Komparasi kinerja peralatan Spektrofotometer uv-vis perkin elmer lambda 3 da hitachi u-2900 dengan Metode Analisa Total Phenolic Content (TPC) menggunakan Reagent Folin Ciocalteue dengan 10 sampel :

- $\quad$ 1. Nilai t hitung yang diperoleh dri percobaan sebesar 0 , .0053

- 2. Nilai t tabel yang diperoleh dari tabel sebesar 2.262.

- 3. Nilai T-hitung < T-tabel, maka H0 diterima dan H1 ditolak, sehingga dapat dikatakan kinerja hasil uji kedua alat sama.

\section{B. Saran}

Perlunya dilakukan Komparasi kinerja alat secara berkala, juga terhadap peralatan yang lain.

\section{DAFTAR PUSTAKA}

[1] Agus, Mikha widiyanto. 2013. Statistika Terapan. Konsep dan Aplikasi dalam Penelitian Bidang Pendidikan, Psikologi dan Ilmu Sosial Lainnya. Jakarta: PT Elex Media Komputindo.

[2] Blainski, A., Gisely Cristiny L., and Palazzo de Mello, J.C.2013. Application and Analysis of the Folin Ciocalteu Method for the Determination of the Total Phenolic Content from Limonium Brasiliense L. Molecules, 18: 6852-6865.

[3] Day, R A, dan Underwood, A L., (2002), Analsis Kimia Kuantitatif Edisi Keenam, Erlangga, Jakarta.

[4] Fu, L., B.T. Xu., R.Y. Gan., Y. Zhang., X.R. Xu., E.Q. Xia. and H.B. Li. 2011. Total Phenolic Contents and Antioxidant Capacities of Herbal and Tea Infusions, International Journal of Molecular Sciences. 12 : 2112-2124.

[5] Pourmorad, F., Hosseinimehr, S.J., Shahabimajd, N., 2006, Antioxidant Activity, Phenol, and Flavonoid Content of Some Selected Iranian Medicinal Plants, African Journal of Biotechnology, 5 (11), 1142-1145.

[6] Rohman, A. Kimia Farmasi Analisis. Yogyakarta: Pustaka Pelajar 2007.

[7] Watson, D.G. (2010).Analisis Farmasi: Buku Ajar untuk Mahasiswa Farmasidan Praktisi Kimia Farmasi, Edisi 2.Penerbit Buku Kedokteran EGC,Jakarta.

[8] https://web.stanford.edu/dept/radiology/cgibin/classes/stats_data_analysis/234_99.html

[9] https://id.wikipedia.org/wiki/Asam_galat 